EESTI NSV TEADUSTE AKADEEMIA TOIMETISED, 24. KOIDE KEEMIA * GEOLOOGIA, 1975, NR, 2

ИЗВЕСТИЯ АКАДЕМИИ НАУК ЭСТОНСКОИ ССР. ТОМ 24 ХИМИЯ * ГЕОЛОГИЯ. $1975, N_{2} 2$

\title{
ПАЛЕОГЕОГРАФИЯ И АБСОЛЮТНАЯ ХРОНОЛОГИЯ ГОЛОЦЕНА ПОЛЯРНОГО УРАЛА
}

Отсутствие до последнего времени радиоуглеродных датировок голоценовых отложений северных районов Урала затрудняло синхронизацию разрезов с прилегающими равнинами. Расчленение голоцена и выделение этапов развития растительности на Полярном Урале производилось исключительно на основе палинологических и стратиграфических материалов. Полученные в 1973 г. первые сведения об абсолютном возрасте голоценовых отложений полностью подтвердили опубликованные ранее данные по истории растительности Полярного Урала в голоцене (Сурова, 1967; Сурова, Троицкий, 1971). Они же выявили, с одной стороны, большое сходство, а с другой - специфические особенности палеогеографии голоцена Полярного Урала по сравнению со смежными территориями.

В настоящей статье приведены результаты палинологических и геохронологических исследований пяти разрезов крушнобупристых торфяников и двух разрезов древнеозерных отложений северного и южного районов Полярного Урала. По этим разрезам получено 11 радиоуглеродных датировок, выполненных в радиоуглеродной лаборатории Института геологии АН ЭССР.

Крупнобугристые торфяники расположены в северной части Полярного Урала, в сквозной долине вблизи оз. Малая Хадата Юган-Лор (абс. высота днища долины 210-220 м), а разрезы древнеозерной толщи с перекрывающим их поверхностным торфяником - на восточном склоне южной части Полярного Урала, на правом берегу р. Большая Лагорта (абс. высота 240-245 м). Расстояние между этими двумя пунктами около $180 \kappa м$.

Современная растительность в сквозных долинах северной расширенной области Полярного Урала представлена кустарниковой тундрой, которая распространена также к западу от хребта. В долинах восточной части гор появляется лесная растительность из лиственницы, ели, березы, ольхи, участки которой прослеживаются далее в восточных предгорьях и на низменности.

В южной суженной части Полярного Урала растительность в горных долинах исключительно тундровая. Леса появляются только на предгорных увалах и широко распространены на низменностях к западу и востоку от хребта. Они представлены елью, лиственницей, березой с подлеском из кустарниковой ольхи и карликовой березки. Лес нигде не заходит в горные долины, хотя увалы имеют нередко бо́льшую абсолютную высоту, чем днища горных долин.

Таким образом, как в северной, так и в южной частях Полярного Урала смена растительных группировок от лесных к тундровым на уровне 
днищ долин не является проявлением высотной поясности, а определяется, как показали наши исследования, в первую очередь особенностями снегонакопления (Троицкий и др., 1966). В горной области снега выпадает в 2-3 раза больше, чем на предгорных увалах и равнинах. Значительное сокращение и без того короткого вегетационного периода за счет более позднего схода снежного покрова в горах является одной из главных причин отсутствия лесной растительности в горных долинах. Появление лесов в долинах восточной половины северной расширенной области Полярного Урала обусловлено здесь малым снегонакоплением в связи с выпадением основной массы осадков в западной части хребта.

По данным радиоуглеродного датирования, изученные разрезы имеют голоценовый возраст. Спорово-пыльцевые диаграммы всех разрезов, выполненные Т. Г. Суровой, очень сходны между собой. В статье приводятся три из них. Две диаграммы (рис. $1, A$ и $Б$ ) характеризуют соседние разрезы озерных осадков на р. Большая Лагорта, различающихся по возрасту и литологии. Здесь мы имеем две озерные толщи как бы вложенные одна в другую, что связано с термокарстовой переработкой первичной озерной равнины и заполнением образовавшегося термокарстового озера более молодыми осадками, позже перекрытыми гюверхностным торфяником (рис. 2). На рис. 3 приведена спорово-пыльцевая диаграмма одного из разрезов торфяных бугров у оз. Малая Хадата. Две другие диаграммы торфяников из этого же района опубликованы ранее (Сурова, 1967; Сурова, Тронцкий, 1971).

По результатам палинологического и радиоуглеродного анализов указанных разрезов на Полярном Урале в голоцене выделено восемь фаз развития растительности, которые хорошо согласуются со схемой Блитта-Сернандера и подразделением голоцена по М. И. Нейштадту (1965).

Рассмотрим основные особенности палеогеографии голоцена Полярного Урала в свете полученных радиоуглеродных данных начиная с эпохи позднего дриаса.

Поздн и й д р и ас $\left(\mathrm{DR}_{3}\right)$ выделяется как время развития своеобразной перигляциальной растительности, образованной сочетанием тундровых и степных элементов (фаза I). В составе спорово-пылыцевых спектров значительное участие принимает пылыца карликовой березки (до $80 \%$ ), а среди травянистых растений Artemisia (до 40\%). Сравнительно много пылыцы маревых (до 25\%), встречены единичные зерна Ephedra. Этому отвечает весьма малое содержание в спектрах папоротникообразных, мхов и плаунов, среди последних преобладают элементы аркто-альпийского распространения: Lycopodium pungens, L. alpinum. Были определены споры L. clavatum, L. selago, Selaginella selaginoides.

Пылыцы древесных пород обнаружено мало, не более содержания в современных поверхностных пробах, что свидетельствует об отсутствии, как и теперь, лесной растительности непосредственно в горных долинах и произрастании редколесий и участков лесов на прилегающих низменностях.

Эта эпоха характеризуется холодными и засушливыми условиями, аналогичными условиям на Русской равнине и в Западной Сибири. В это время на Полярном Урале были развиты карово-долинные ледники. Из расчета скорости накопления озерных осадков в разрезе р. Большая Лагорта и радиоуглеродной датировки вышележащего слоя песков в $9860 \pm 75$ лет (Tln-25) верхняя граница рассматриваемото периода датируется примерно в интервале $10300-10400$ лет назад, что хорошо согласуется с определением возраста поздне-послеледникового рубежа в других районах северной Евразии. 


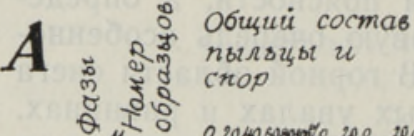

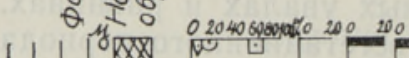

Пыльца травя-

Hucmolx pac- Cnopb

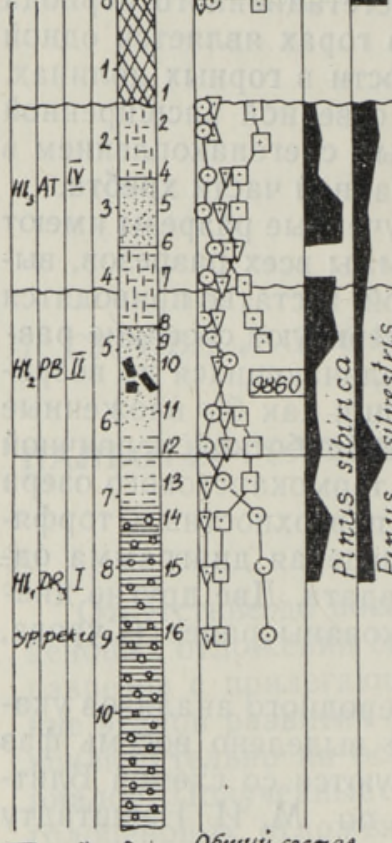

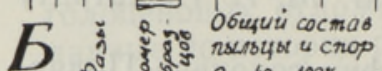

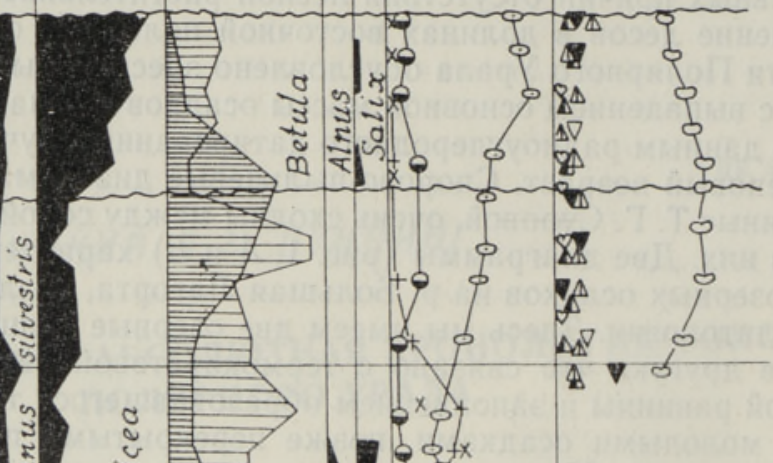

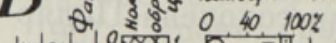

$204060 \% 2040 \quad 6080 \% 0 \quad 10 \% 20 \quad 4060 \quad 80 \% 0 \quad 20 \quad 40 \quad 60 \quad 80 \%$

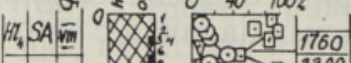

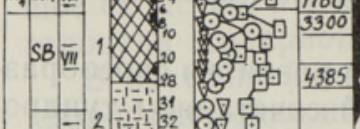

$\overline{\text { Vi }}^{2}$

$\mathrm{H}_{3}$

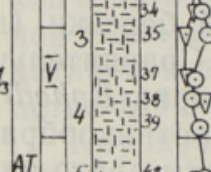

AT

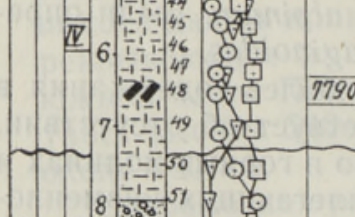

Hitiples I

8 क्ष्:

we ockug 9
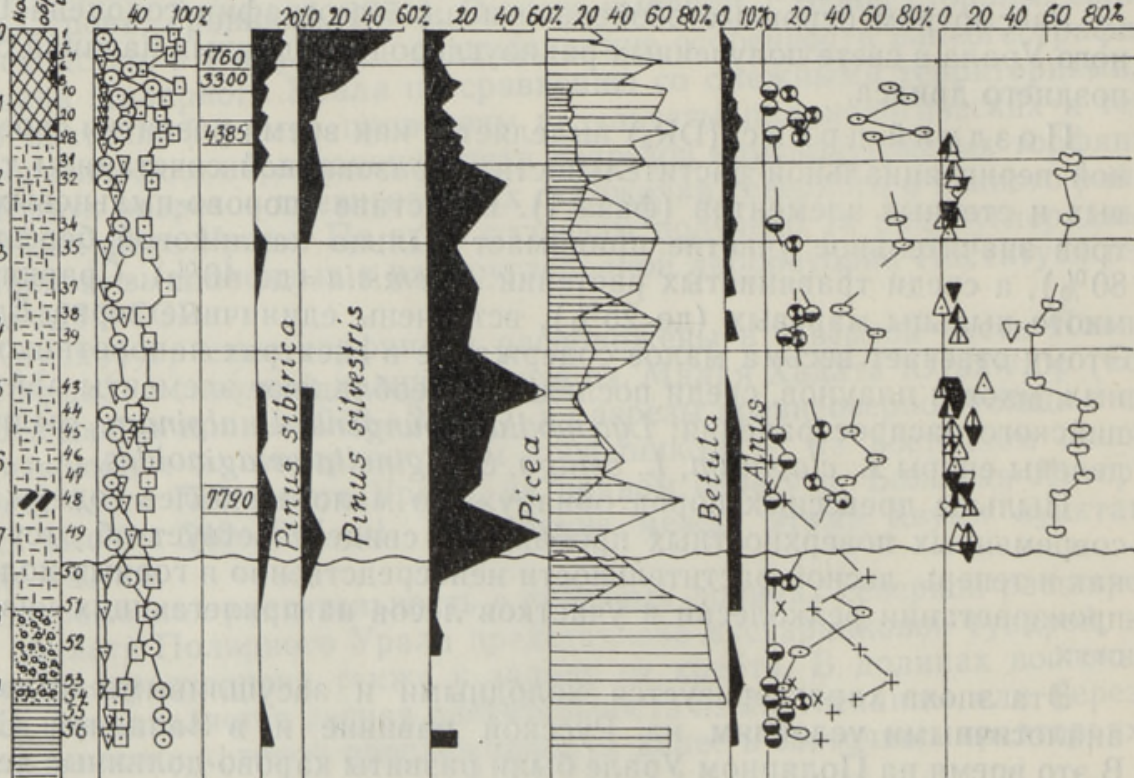

Truroua mpasr

Hucmotx pac.

мении

Cropst

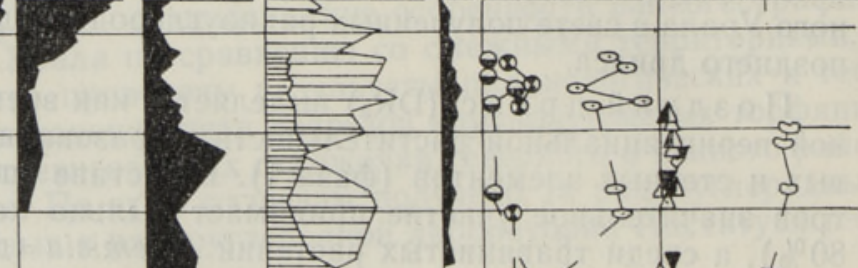

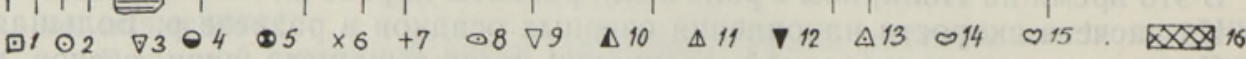
ㄴ-1-17. 
Пребореальный пе риод (РВ) характеризуется распространением в долинах Полярного Урала березово-елового редколесья по ерниковой тундре (фаза II). Резко сокращается количество пыльцы полыни. Одновременно в растительном покрове сильно возрастает участие папоротников, что указывает на увлажнение и потепление климата по сравнению с $\mathrm{DR}_{3}$. На других спорово-пыльцевых диаграммах (рис. 1, Б и 3) фаза II не выражена вследствие размыва соответствующего горизонта осадков.

Отнесение фазы ІІ к РВ подтверждается радиоуглеродной датировкой остатков древесины из разреза р. Большая Лагорта в $9860 \pm 75$ лет (Tln-25). Во второй половине PB отмечается более холодолюбивый пыльцевой спектр, что соответствует, вероятно, переславскому похолоданию, выделяемому на Русской равнине (Хотинский, 1972). Для датирования верхней границы РВ на Полярном Урале данных недостаточно. Однако на Русской равнине и Среднем Урале возраст ее определяется около 9200 лет (Хотинский, 1968).

Бореальный период (BО)

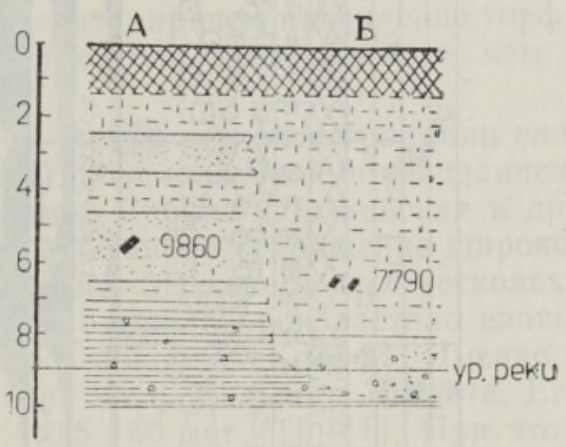

Рис. 2. Разрез древнеозерных отложений на р. Большая Лагорта. Условные обозначения те же, что и на рис. 1. выражен лишь на одной из приведенных спорово-пыльцевых диапрамм (фаза III, рис. 3). Значительно лучше он представлен на ранее опубликованной диаграмме торфяника оз. Малая Хадата (Сурова, Троицкий, 1971), базальный горизонт которого теперь датирован в $8670 \pm 100$ лет (Tln-85). Таким образом, формирование торфяников на Полярном Урале началось в ВО эпоху. В это время в долинах Полярного Урала было распространено березово-еловое редколесье с участием лиственницы. В спорово-пыльцевых спектрах содержание пыльцы ели составляет 10-19\% и лиственницы до 5\% (Сурова, Троицкий, 1971). Пылыца лиственницы, как известно, плохо сохраняется в ископаемом состоянии. В поверхностных пробах, взятых в лиственничном редколесье под кронами деревьев, ее количество не превышало $2-3 \%$. Следовательно, содержание пыльцы лиственницы до $5 \%$ может свидетельствовать о произрастании здесь этой породы. О произрастании ели говорят также находки ее древесины в торфе.

Климат ВО был несколько теплее современного, на что, в частности, указывает присутствие вахты в торфе, ныне здесь не произрастающей. Однако на Полярном Урале ель не получила еще максимального распространения, как это устанавливается для севера Западной Сибири (Левковская и др., 1970; Пьявченко, 1971).

А тл анти чески й период (AT) характеризуется широким распространением еловых лесов. Причем растительность Полярного Урала,

Рис. 1. Спорово-пыльцевые диаграммы разреза древнеозерных отложений на р. Большая Лагорта. $A-$ левая и 5 - правая части разреза. 1 - древесные, 2 - травянистые, 3 - споры, 4 - злаки, 5 - разнотравье, 6 - маревые, 7 - Artemisia, 8 - осоковые, 9 - Bryales, 10 - Lycopodium pungens, 11 - Lycopodium alpinum, 12 - Sphagnum, 13 - Lycopodium annotinum, 14 - Polypodiaceae, $15-$ Selaginella selaginoides, $16-$ торф, 17 - озерные суглинки, 18 - песок с галькой, 19 - песок, 20 - глинистые пески, 21 - глины, 22 - остатки древесины, 


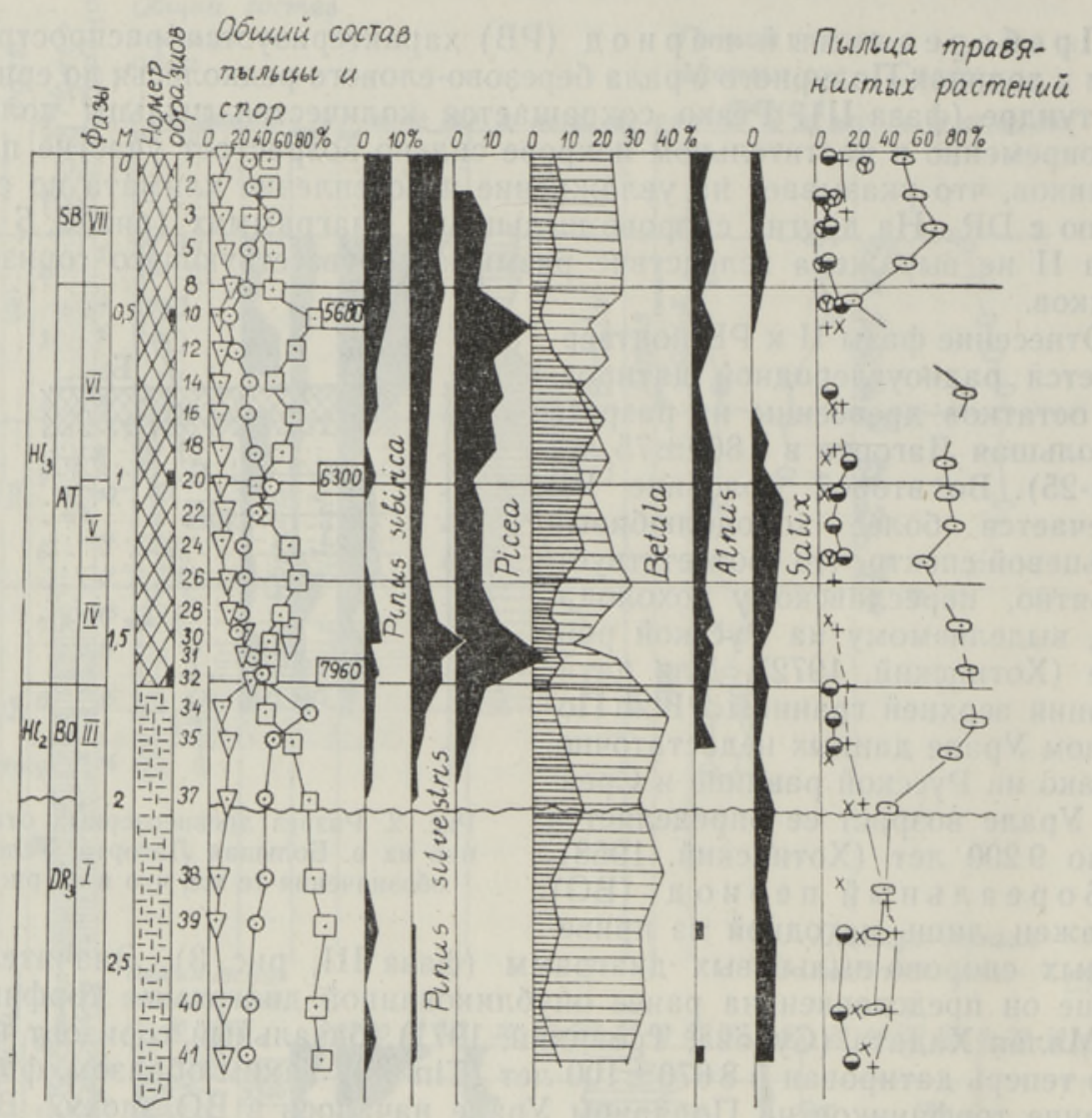

Рис. 3. Спорово-пыльцевая диаграмма разреза бугристого торфяника у оз. Малая Хадата. Условные обозначения те же, что и на рис. 1.

в отличие от прилегающих равнин, развивалась в три этапа (фазы IV, V и VI). Хронологические рамки АT периода на Полярном Урале четко устанавливаются по восьми датированным образцам в интервале 8000 4500 лет назад, что хорошо совпадает с представлением о возрасте этого периода в Европе.

В начале AT периода (фаза IV) ель на Полярном Урале получает максимальное распространение. Содержание ее пыльцы в пыльцевых спектрах достигает $65 \%$, образуя один или два пика. Этот нижний максимум ели датируется по остаткам древесины в озерных отложениях на р. Большая Лагорта в $7790 \pm 80$ лет (Tln-40) и базальному горизонту торфа в торфянике у оз. Малая Хадата в $7960 \pm 100$ лет (Tln-86). В это время происходит смыкание лесов западного и восточного склонов Полярного Урала по сквозным горным долинам, а на равнинах продвижение границы леса к северу.

В середине АТ периода в составе лесов происходит значительное сокращение ели и увеличение древесной сосны (фаза V). В торфяниках у оз. Малая Хадата встречены погребенные остатки стволов белокорой березы диаметром до $25 \mathrm{~cm}$. Для этой фазы получены датировки торфа $6745 \pm 70$ лет (Tln-84) и $6315 \pm 70$ лет (Tln-64).

Третий этап АТ периода выделяется новым развитием еловых лесов (верхний максимум ели, фаза VI). Возрастает также количество пыльцы 
сосны, кедра и лиственницы. Лесная растительность по-прежнему занимает горные долины Полярного Урала, а в предгорьях и на равнинах продвигается в пределы современной тундры на 200-400 км (Кац, Кац, 1946). Температура вегетационного периода была на $3-4^{\circ}$ выше современной, что привело к полному стаиванию ледников на Урале (Троицкий и др., 1966). Для третьего этапа АТ периода получены радиоуглеродные датировки торфа у оз. Малая Хадата $6280 \pm 70$ лет (Tln-83) и $5680 \pm 120$ лет $(\mathrm{T} \ln -56)$.

Следует отметить, что за АТ период образовалась основная масса торфа в торфяниках вблизи оз. Малая Хадата, причем накопление торфа во второй половине этого периода происходило вдвое быстрее, чем в первой.

С убборе альный пе р иод (SB) - время резкой деградации еловых лесов на Полярном Урале (фаза VII), обусловленной похолоданием, что отмечается также для севера Западной Сибири (Левковская и др., 1970). На Русской равнине в это время произошло сокращение широколиственных лесов (Хотинский, 1972). Однако SB период был несколько теплее современного. В долинах Полярного Урала произрастало еловолиственничное редколесье и продолжалось накопление торфа. Именно в это время начал формироваться торфяник на р. Большая Лагорта. Его базалыный горизонт имеет датировку $4385 \pm 60$ лет $(\mathrm{T} \ln -41)$. При этом скорость накопления торфа в течение этого периода была такой же, как в торфяниках оз. Малая Хадата во второй половине АТ времени (810 см за 100 лет). Согласно указанной датировке и спорово-пыльцевой диаграмме (рис. $1, Б$ ), возраст нижней границы SB периода устанавливается примерно в 4500 лет, что соответствует европейским разрезам.

С убатл антически й период (SA) характеризуется дальнейшим отступанием лесной растительности, которая полностью оставляет горные долины в южной части Полярного Урала и в западной половине северной расширенной его части, уступая место ерниковой тундре (фаза VIII). Количество пылыцы ели и березы меньше, чем в современных спорово-пылыцевых спектрах. Вместе с тем резко возрастает содержание пыльцы сосны (до 65\%) и кедра (до 20\%), особенно в поверхностных пробах, что отмечено также для севера Западной Сибири (Кац, Кац, 1946; Левковская и др., 1970; Пьявченко, 1971). В составе современной растительности сосна в изучаемом районе отсутствует, следовательно, пыльца сосны была заносной. По нашему мнению, возрастание пыльцы сосны и кедра в условиях деградации еловых лесов связано с усилением процесса атмосферной циркуляции в SA период по сравнению с предшествующими эпохами голоцена, что должно было привести к увеличению количества осадков. Похолодание климата и увеличение осадков, прежде всего онежности, обусловили деградацию лесной растительности и одновременно возобновление карового оледенения в северных районах Урала.

Возраст границы SB и SA времени на Полярном Урале определяется в 2500 лет, что достаточно надежно устанавливается по двум датировкам торфа в торфянике на р. Большая Лагорта (3 300 \pm 110 лет $(T \ln -55)$ и $1760 \pm 60$ лет (Tln-42)) и спорово-пыльцевой диаграмме (рис. 1, Б). B SA периоде скорость накопления торфа замедлилась по сравнению с SB временем в несколько раз и составила 2 см за 100 лет. В это время началось промерзание торфяников, а в условиях сильного заболачивания их вспучивание и образование торфяных бугров, поверхность которых подвергалась ветровой эрозии. В результате верхняя часть торфа на многих буграх была снесена, как это установлено на торфяниках оз. Малая Хадата, в спорово-пылыцевых профилях которой отсутствует SA и часть SB 
периодов. Это же явление отмечается и для бугристых торфяников Западной Сибири (Кац, Кац, 1946; Пьявченко, 1971).

Итак, полученные первые радиоуглеродные датировки голоценовых отложений выявили почти полное совпадение основных возрастных рубежей голоцена Полярного Урала с европейскими и сибирскими разрезами. Вместе с тем установлены некоторые особенности в палеогеографии Полярного Урала в отдельные этапы голоцена. Одним из важных отличий развития растительности на Полярном Урале является приуроченность максимального распространения еловых лесов к АТ периоду, а не к ВО, как это отмечено для севера Западной Сибири (Левковская и др., 1970; Пьявченко, 1971). Причем для АТ периода на Полярном Урале характерно трехфазовое развитие растительности с двумя максимумами ели (в начале и конце периода), а не двухфазовое, как это имело место на Русской равнине и в Сибири.

ВО период на Полярном Урале по ограниченности пооизрастания ели более сходен с таковым на Русской равнине и Среднем Урале, где климат отличался достаточной континентальностью, что привело к повсеместному распространению березы и задержало развитие широколиственных и темнохвойных лесов (Хотинский, 1968, 1972).

На рубеже АТ и SB периодов на Полярном Урале, как и в прилегающих равнинах, четко фиксируется похолодание, обусловившее деградацию лесной растительности, усилившуюся в SA время.

Специфические особенности палеогеографии голоцена Полярного Урала связаны в первую очередь с его северным положением, а также со своеобразием развития растительности в горных условиях, где на произрастание лесов влияли не только изменения температуры, но и увеличение количества осадков и прежде всего снежности, приводившие к деградации лесов в связи с сокращением вегетационного периода за счет более позднего схода снежного покрова.

\section{ЛИТЕРАТУРА}

К ац Н. Я., К а ц С. В. 1946. История растительности болот севера Сибнри как показатель изменений послеледникового ландшафта. В сб.: Проблемы палеогеографии четвертичного периода. Тр. Ин-та географии, вып. 37.

Л евковска я Г. М., Кинд Н. В., З а вельский Ф. С., Форов а В. С. 1970. Абсолютный возраст торфяников в районе г. Игарка и расчленение голоцена Западной Сибири. Бюл. Комис. по изучению четвертичного периода, № 37

Н е й. т а д т М. И. 1965. Некоторые итоги изучения отложений голоцена. В сб.: Палео. география и хронология верхнего плейстоцена и голоцена по данным радноуглеродното метода. М.

П ь я в ч е н ко Н. И. 1971. К изучению палеогеографии севера Западной Сибири в голоцене. В сб.: Палинология голоцена. М.

Суров а Т. Г. 1967. О развитии растительности Полярного Урала в голоцене. Вестник Моск. ун-та, биология. почвоведение, № 2.

С уров а Т. Г., Т р о и ки й Л. С. 1971. О динамике растительного покрова, климата и оледенения на Полярном Урале в голоцене (по данным палинологических исследований). В сб.: Палинология голоцена. М.

Т роицкий Л. С.. Ходаков В. Г.. Михалев В. И., Гуськов А. С., Лебе де в а И. М., Ада ме нко В. Н., Жи в ович Л. А. 1966. Оледенение Урала. (Результаты исследования по программе МГГ, гляциология, № 16). М.

$\mathrm{X}$ о ти н ский Н. А. 1968. Некоторые вопросы хронологни и палеогеографин голоцена Среднего Урала. Бюл. Комис. по изучению четвертичного периода, № 35.

Х о т и н ск и й Н. А. 1972. Палеогеотрафические итоги корреляции этапов развития растительности Северной Евразии в голоцене. Автореф. дис. на соискание учен. степени д-ра геогр. наук. $M$.

Ннститут географии

Академии наук СССР

Поступила в редакцию 27/VI 1974

Ннститут геологии

Академии наук Эстонской ССР 
T. SUROVA, L. TROITSKI, J.-M. PUNNING

\section{POLAAR-URAALI HOLOTSEENI PALEOGEOGRAAFIA JA ABSOLUUTNE KRONOLOOGIA}

Artiklis tuuakse ära rea Polaar-Uraali läbilõigete palünoloogilise analüüsi tulemused ning setete absoluutsed vanused. Taimkatte arengu põhiliseks omapäraks on kuusemetsade maksimaalne levik atlantilisel kliimaperioodil. Atlantilise ja subboreaalse perioodi piiril leidis aset jahenemine. Paleogeograafilised iseärasused on tingitud regiooni geograafilisest asendist.

Absoluutsed vanused võimaldavad määrata üksikute kliimaperioodide kestust.

\section{SUROVA, L. TROITSKI, J.-M. PUNNING}

\section{HOLOCENE PALAEOGEOGRAPHY AND ABSOLUTE CHRONOLOGY OF THE POLAR URALS}

The authors present the results of the palynological analysis of the profiles in the Polar Urals and the absolute datings of the deposits. The principal feature of the development of the vegetative coverage is the maximal distribution of fir forests in the Atlantic period. A cooling of the climate took place at the border of the Atlantic and the Subboreal. The palaeogeographical peculiarities have been called forth by the geographical position of the region.

The absolute datings enable to determine the duration of the separate climatic periods. 